\title{
Standardisation Process of Saye, a Traditional Polyherbal Formulation Remedy for Malaria: Physico-chemical Analysis and Phytochemical Investigation
}

\author{
Jules Yoda ${ }^{1,3, *}$, Jean Claude Ouedraogo ${ }^{2}$, Salfo Ouedraogo ${ }^{1}$, Maminata Traore-Coulibaly ${ }^{1}$, \\ Felix Kini ${ }^{1}$, Marius Lompo ${ }^{1}$, Sylvin Ouedraogo ${ }^{1}$ \\ ${ }^{1}$ Department of Medicine, Traditional Pharmacopoeia and Pharmacy, Research Institute for Health Sciences (MEPHATRA-PH /IRSS), \\ Ouagadougou, Burkina Faso \\ ${ }^{2}$ Organic Chemistry and Reactivity Laboratory, University Joseph KI-ZERBO, Ouagadougou, Burkina Faso \\ ${ }^{3}$ Molecular Chemistry and Materials Laboratory (LCMM)/Organic Chemistry and Phytochemistry Team (ECOP), University Joseph \\ KI-ZERBO, Ouagadougou, Burkina Faso
}

\author{
Email address: \\ jules_yoda@yahoo.fr (J. Yoda) \\ ${ }^{*}$ Corresponding author
}

\section{To cite this article:}

Jules Yoda, Jean Claude Ouedraogo, Salfo Ouedraogo, Maminata Traore-Coulibaly, Felix Kini, Marius Lompo, Sylvin Ouedraogo. Standardisation Process of Saye, a Traditional Polyherbal Formulation Remedy for Malaria: Physico-chemical Analysis and Phytochemical Investigation. Science Journal of Analytical Chemistry. Vol. 8, No. 1, 2020, pp. 33-40. doi: 10.11648/j.sjac.20200801.16

Received: February 18, 2020; Accepted: March 3, 2020; Published: March 10, 2020

\begin{abstract}
The use of herbal drugs for primary care is nowadays central to the global health system. In developing countries, it meets both economic and socio-cultural requirements. However, this increase about the use of herbal medicines has led to various forms of abuses related to factors that are generally extrinsic to the drug, such as incorrect botanical identification, falsification, fungal or bacterial contamination, etc. The need for the standardization of herbal drugs is more than ever important for the viability of phytotherapy. This study focuses on saye, a mixture of three plants including the root of Cochlospermum planchonii; the whole plant of Phyllanthus amarus and the leaves of Cassia alata. This traditional polyherbal formulation that we intend to promote is used in Burkina Faso as a herbal tea to treat malaria. In this present study, the aim is to control the quality and standardization of the saye and its different components in order to produce an antimalarial phytomedicine. More precisely, we present here, the phytochemical composition and physico-chemical study of the mixture and the vegetable raw materials. In this study, we are particularly concerned with the study of organoleptic properties, moisture content, total ash content, successive extraction yields, fingerprinting by thin layer chromatography, phytochemical screening and total flavonoids content. To evaluate the content of flavonoids selected as chemical bioactive marker, we used a method of spectrophotometric assay. The phytochemical study established fingerprints, identified the main secondary metabolites and determined the total flavonoid content in a selective extract of the saye. The physico-chemical analysis provided satisfactory results on the main indices, such as moisture content, total ash, heavy metals, etc. These results indicate a good treatment of plant raw materials and will certainly be used for the standardization of the drug and its quality control for future clinical studies.
\end{abstract}

Keywords: Saye, Cochlospermum Planchonii, Phyllanthus Amarus, Cassia Alata, Standardization, Antimalarial

\section{Introduction}

Standardisation is defined as the set of measures taken during the manufacturing process related to quality control in order to obtain products of reproducible quality. While quality control aims to verify the previously established qualitative and quantitative standards for: raw material, intermediate product, finished product. Standardization therefore consists in validating quality procedures at all stages of manufacturing, from plant raw materials to finished products and intermediate products such as extracts, in order 
to obtain a well-defined standards. The standardization of medicinal plants thus contributes to ensuring quality, efficiency, safety and reproducibility [1-9]. However, due to the complex nature and inherent variability of the constituents of plant drugs, it is difficult to establish quality control parameters, although modern analytical techniques must overcome this problem [4]. In addition, the constituents responsible of the therapeutic effects claimed are often unknown or only partially explained. The use of a combination of recipes based on several herbal (polyherbal), as used in traditional practices, further complicates the situation. It is common to have up to 3 or more different herbal drugs in the same recipe. Thus, variation from batch to batch begins with the collection of the raw material itself in the absence of any reference standard for identification. These variations increase during storage and further processing [6-8]. Consequently for herbal products (plant raw materials, preparations and finished herbal products) standardization should cover the entire field of study, from the cultivation of the medicinal plant to its clinical application [2]. In this study, we investigate the quality of the saye. This traditional recipe that we intend to promote is used in Burkina Faso (West Africa) as a herbal tea to fight malaria for more than 30 years $[10,11]$. Regarding malaria treatment, several schemes have been shown to be ineffective in the long term. These therapeutic failures and the development of resistance are the result of genetic mutations in the parasite, often linked to certain characteristics of the active molecules, in particular: bioavailability, half-life of the product in the organism and the therapeutic index $[12,13]$. Thus, the principle was created combining several active molecules with complementary characteristics to increase the effectiveness of the treatment and counter the evolution of chemoresistance [14-16]. The saye that is the subject of our attention in this study responds to this new situation. The saye is a mixture of three plants: the root of Cochlospermum planchonii known locally as N'Dribala; the whole plant of Phyllanthus amarus and the leaves of Cassia alata [10]. We precisely analyze the chemical composition and physicochemical parameters of this polyberbal and its three components in a standardization process for the production of a drug.

\section{Materials and Methods}

\subsection{Physico-Chemical Analysis}

The physico-chemical parameters investigated for this study are: physical and organoleptic characteristics, $\mathrm{pH}$, granulometry analysis, moisture content, total ash content and heavy metal content.

\subsubsection{Sample Collection and Preparation}

The powder of cassia alata leaves, the powder of cochlospermum planchonii root, the powder of the whole plant of phyllantus amarus and the Saye, were all provided by the Phytofla laboratory, a laboratory specialized in phythotheurapy in Burkina Faso. sample collection, botanical authentication and processing were performed by the same laboratory (Figures 1-3).

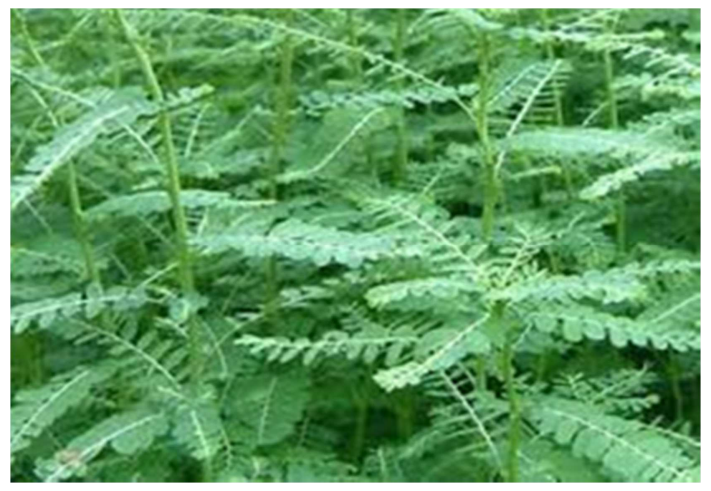

Figure 1. Phyllantus amarus.

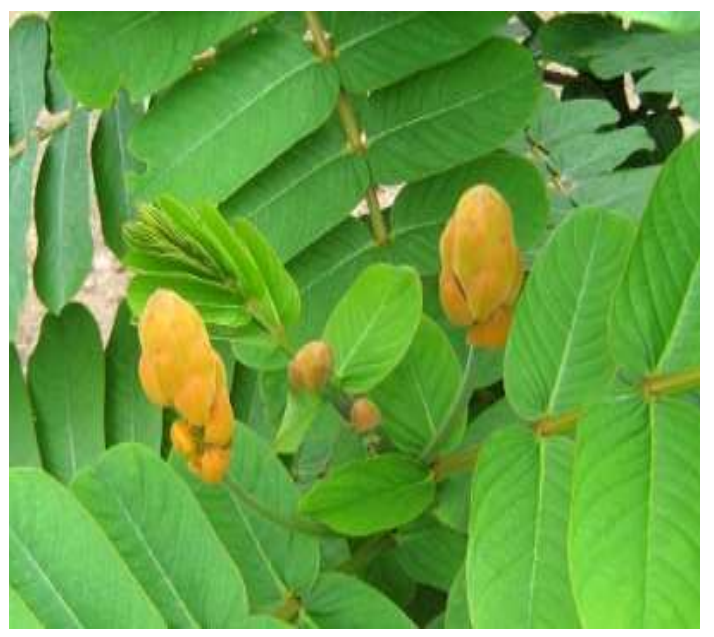

Figure 2. Cassia alata.

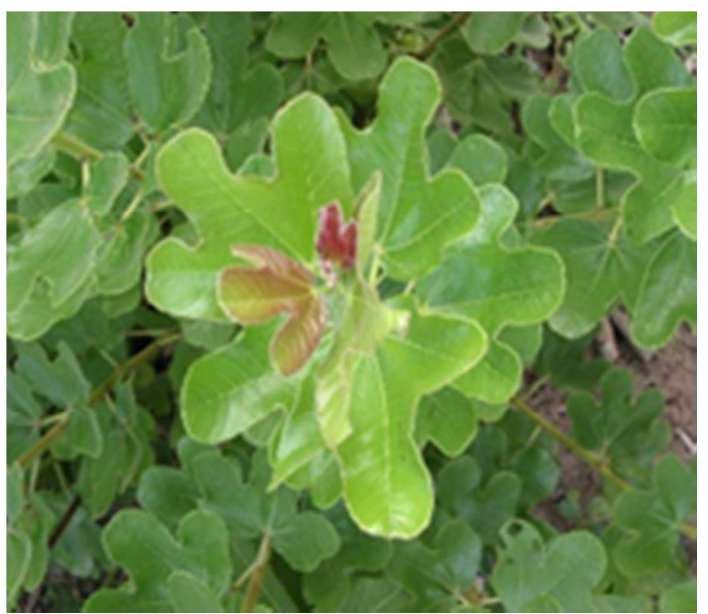

Figure 3. Cochlospermum planchonii.

\subsubsection{Physical and Organoleptic Test}

The examination of organoleptic characteristics includes analyses of the general shape, colour, smell, taste and texture of the drug. The macroscopic characteristics (appearance and color) were observed with the naked eye. The organoleptic characteristics were determined by tasting the powder and the odor by sniffing [17]. 


\subsubsection{Determination of $\mathrm{pH}$}

$1 \mathrm{~g}$ of sample was measured and then transferred to a $25 \mathrm{ml}$ conical flask; $25 \mathrm{ml}$ of distilled water was added and heated on a hot plate to boil and allowed to cool. The aqueous extracts of medicinal herbs were then filtered into another volumetric flask and filled with distilled water to the mark. The $\mathrm{pH}$ is determined using a calibrated $\mathrm{pH}$ meter [18]

\subsubsection{Granulometric Analysis}

Particle size was determined by the international pharmacopoeia filtering method [19-20]. A column of ten (10) sieves with different mesh sizes $(0.1 \mathrm{~mm}$ to $1.6 \mathrm{~mm})$ is used. The mass of each screen must be weighed individually before being placed on the vibrator. Then $100 \mathrm{~g}$ of powder will be introduced onto the upper sieve (mesh opening 1.6 $\mathrm{mm}$ ). When the device is switched on, the screen column is subjected to vibrations that set the powder in movement: particles smaller than the opening of the screen then pass over the lower screen, and so on to the bottom of the column [17].

\subsubsection{Moisture Content}

A mass of $1 \mathrm{~g}$ of powder sample was placed a in the crucible and dried in an oven at $105^{\circ} \mathrm{C}$. After cooling, the steamed test sample is weighed and the resulting mass is recorded. The drying process is repeated until the moisture content attained a constant value [17-18].

\subsubsection{Heavy Metals}

The determination of heavy metals in vegetable powder will be carried out by University Joseph Ki-Zerbo. The heavy metals sought are total arsenic (As), mercury (Hg), cadmium $(\mathrm{Cd})$ and lead $(\mathrm{Pb})$. The analyses were carried out on a flame atomic absorption spectrometry (FAAS) of the VARIAN AA 240FS type [17, 21].

\subsubsection{Total Ash Content}

The total ash content was determined according to the 6th edition of the European Pharmacopoeia by calcining 1g of each vegetable powder in an oven at $600^{\circ} \mathrm{C}$. The total ash content was expressed as a percentage [21].

\subsection{Phytochemical Composition}

\subsubsection{Extraction Yield}

A mass of $2 \mathrm{~g}$ of powder from each sample will be extracted with n-hexane $(50 \mathrm{ml})$ by maceration for $24 \mathrm{~h}$. The mixture is then filtered using wattman paper. The marc is again extracted with $50 \mathrm{ml}$ of hexane for $30 \mathrm{~min}$ and filtered. The two extracts are combined and evaporated dry using a rotary evaporator to give dry extracts. The marc from the extraction with $\mathrm{n}$-hexane is dried and extracted successively with dichloromethane, ethyl acetate and methanol according to the same procedure as the hexane extraction. The dry extracts obtained are weighed with a precision balance and the extraction yields evaluated.

\subsubsection{Fingerprinting by Thin Layer Chromatography (TLC)}

Each sample was solubilized in its extraction solvent at a concentration of $10 \mathrm{mg} / \mathrm{ml}$ and $10 \mu \mathrm{L}$ was deposited on a 60 F254 silica gel plate (glass support). The chromatographic plate is then immersed in the tank containing the desired mobile phase for the development of the chromatogram over a distance of $8 \mathrm{~cm}$. After the chromatogram has been developed, the chromatographic plate is visualized using a UV lamp. The TLC was conducted according to the general methods of the Pharmacopoeia [20].

\subsubsection{Determination of the Phytochemical Constituent}

The phytochemical screening of the plants extracts was carried out by simple qualitative and quantitative methods used by earlier researchers [22-25].

\section{Results and Discussion}

\subsection{Physical and Organoleptic Test}

To obtain the organoleptic characteristics, we determined the colour, odour and flavour of the crude powder of the saye and each of the three constituent plants (Table 1).

Table 1. Organoleptic characteristics of the saye and its components.

\begin{tabular}{llll}
\hline Crude powder & Colour & Odour & Flavour \\
\hline Cassia alata & greenish & odourless & flavourless \\
Phyllantus amarus & greenish & odourless & flavourless \\
Cochlospermum planchonii & russet & odourless & bitter \\
Saye & greenish & odourless & slightly bitter \\
\hline
\end{tabular}

Cassia alata and phyllantus amarus are odourless and flavourless, only the green colour can be used to characterize them. However, cochlospermum planchonii is recognized even in traditional environments, for its bitter related to the presence of certain secondary metabolites in the plant. The greenish colour and slightly bitter taste of the crude powder of the saye is particularly related to the presence of the cochlospermum planchonii in the mixture. These tests, although preliminary, sometimes make it possible to immediately recognize the plant drug, to check its degree of purity according to the presence or absence of foreign elements, moulds, etc. And possibly to detect adulteration or falsification $[4,26]$.

\subsection{Granulometric Analysis}

Before extraction, the drugs, which are in the form of dried fragments, are crushed until they reach a degree of granulometry adapted to an optimal dissolution of the constituents to be identified. The granulometric method chosen represents a compromise between maximum extraction degree, easy filtration and absence of settling 
(Table 2). In the case of aqueous extraction, the powder is moistened to prevent late swelling.

Table 2. Granulometry of the saye and its components.

\begin{tabular}{lllllllll}
\hline Sieve & Cassia alata & \multicolumn{3}{l}{ Phyllantus amarus } & \multicolumn{2}{l}{ Cochlospermum planchonii } & Saye \\
\hline M (mm) & P1 (\%) & P2 (\%) & P1 (\%) & P2 (\%) & P1 (\%) & P2 (\%) & P1 (\%) & P2 (\%) \\
\hline 1,60 & 40,6 & 40,6 & 3,42 & 3,42 & 57,56 & 57,56 & 22,02 & 22,02 \\
1,25 & 6,86 & 47,46 & 0,44 & 3,86 & 2,52 & 60,08 & 1,62 & 23,64 \\
1,00 & 11,26 & 58,72 & 0,78 & 4,64 & 3,58 & 63,66 & 7,42 & 31,06 \\
0,90 & 2,94 & 61,66 & 1,08 & 5,72 & 1,34 & 65 & 0,9 & 31,96 \\
0,71 & 1,88 & 63,54 & 2,96 & 8,68 & 2,24 & 67,24 & 0,44 & 32,4 \\
0,63 & 0,46 & 64 & 2,28 & 10,96 & 2,02 & 69,26 & 0,86 & 33,26 \\
0,50 & 4,44 & 68,44 & 5 & 15,96 & 3,86 & 73,12 & 2,78 & 36,04 \\
0,40 & 1,96 & 70,4 & 5,1 & 21,06 & 7,4 & 80,52 & 3,82 & 39,86 \\
0,315 & 3,54 & 73,94 & 12,48 & 33,54 & 6,22 & 86,74 & 8,24 & 48,1 \\
0,1 & 20,68 & 94,62 & 59,22 & 92,76 & 13,18 & 99,92 & 41,96 & 90,06 \\
Receiver bottom & 4,08 & 98,7 & 8,16 & 99,88 & 1,06 & 100,98 & 9,9 & 99,96 \\
\hline
\end{tabular}

M: Mesh of the different sieves; P1: Percentage of retained by the sieve; P2: Cumulative percentage (\%);

The results of the granulometry show that the vegetable raw material has been satisfactorily ground. For the analyses, it is recommended to continue with the accumulation of powders of sieves of mesh size 0.5 to $0.1 \mathrm{~mm}$ [19-20]. The diagram below (Figure 4) shows the mass of powder in relation to the different types of sieves used. an analysis of the data presented in this figure, it can be seen that most of the different powders have been sieved through meshes between 0.5 and $0.1 \mathrm{~mm}$. This proves the good granulometric quality of the powders that will be used for the study.

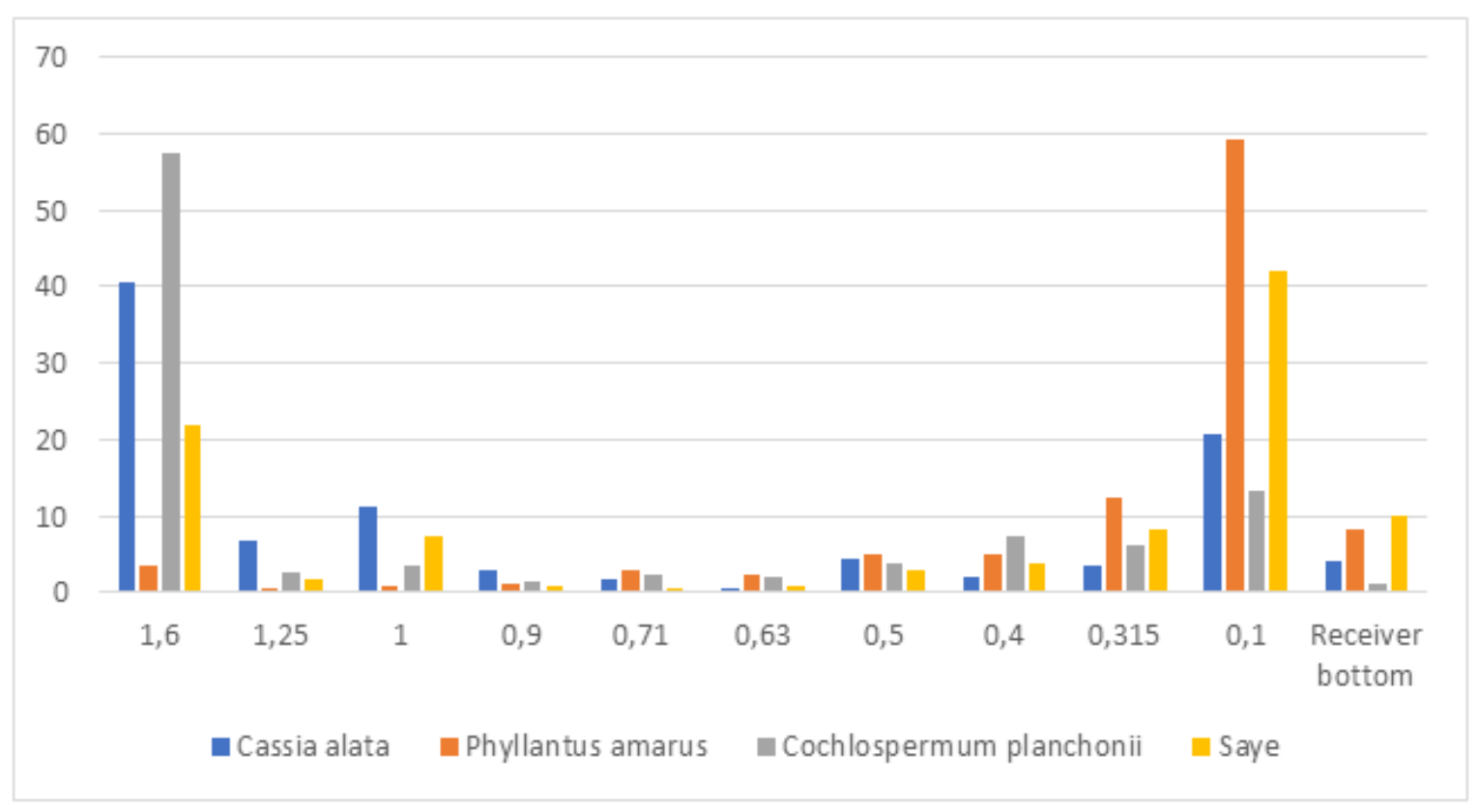

Figure 4. Diagram representing the powder mass for the different types of sieves employed.

\subsection{Moisture Content, Total Ash Content and pH Measurement}

Table 3. Total ash content, moisture content and $\mathrm{pH}$.

\begin{tabular}{llll}
\hline Vegetable powder & Total ash content $(\%)$ & Moisture content $(\%)$ & pH $\left(\mathbf{2 5} \mathbf{C}^{\circ} \mathbf{C}\right)$ \\
\hline $\mathrm{Ca}$ & $8,62 \pm 0,05$ & $5,21 \pm 0,15$ & 5,4 \\
$\mathrm{Cp}$ & $4,88 \pm 0,05$ & $7,14 \pm 0,16$ & 4,2 \\
$\mathrm{~Pa}$ & $7,50 \pm 0,05$ & $5,74 \pm 0,09$ & 5,1 \\
$\mathrm{Sa}$ & $7,19 \pm 0,05$ & $7,11 \pm 0,21$ & 4,9 \\
\hline
\end{tabular}

Ca: Cassia alata, Cp: Cochlospermum planchonii, Pa: Phyllantus amarus, Sa: Saye

The moisture content, total ash percentages and different measured $\mathrm{pH}$ values were determined and recorded in the above table (Table 3). The total ash content values are low, the lowest is 4.88 for cochlospermum planchonii powder sample and the highest is 8.62 for cassia alata powder sample. These values are below the limit value, which is generally $15 \%$. These values indicate good treatment of the plant material (roots and leaves). The moisture content of the different 
powders varies between 5.21 and $7.14 \%$. Since these values are less than $10 \%$, it can be said that the powders are dry and can be stored for a long period without the development of moulds or yeasts [27]. The $\mathrm{pH}$ values measured vary between
4 and 6 . The various samples in aqueous solution revealed the $\mathrm{pH}$ of the components of the saye in solution: $\mathrm{pH} 4$ acid for cochlospermum planchonii and a $\mathrm{pH} 5.4$ for cassia alata. For the saye, there is a low acid $\mathrm{pH} 4.9$.

\subsection{Determination of Heavy Metals}

Table 4. Determination of heavy metals.

\begin{tabular}{|c|c|c|c|c|}
\hline \multirow{2}{*}{$\begin{array}{l}\text { Vegetable } \\
\text { powder }\end{array}$} & \multicolumn{4}{|l|}{ content (ppm) } \\
\hline & Total arsenic (RSD \%) & Mercury (RSD \%) & Cadmin (RSD \%) & Plomb (RSD \%) \\
\hline $\mathrm{Ca}$ & $0,43(3,9)$ & $<\mathrm{DL}$ & $0,1(8,4)$ & $0,10(18,3)$ \\
\hline $\mathrm{Cp}$ & $0,565(1,8)$ & $<\mathrm{DL}$ & $0,135(1,3)$ & $0,135(1,8)$ \\
\hline $\mathrm{Pa}$ & $0,54(2,0)$ & $<\mathrm{DL}$ & $0,125(1,8)$ & $0,115(2,3)$ \\
\hline
\end{tabular}

DL: Determination Limit; RSD: Relative Standard Deviation

The heavy metals analysis focused on the three powders of the saye mixture. The values are recorded in the table above (Table 4). The permitted limit values are: Arsenic $\leq 2 \mathrm{ppm}$; lead $\leq 5 \mathrm{ppm}$; mercury $\leq 1 \mathrm{ppm}$; cadmium $\leq 1 \mathrm{ppm}[27]$. the heavy metals content of all our samples is below the permitted limit values. These obviously attest to the good quality of the soil on which the harvests were carried out (absence of metal pollutants).

\subsection{Extraction and Establishment of the Chromatographic Fingerprint}

\subsubsection{Extraction}

The extracts are obtained by depleting the different powders with solvents in order of increasing polarity. The extraction yield obtained from $2 \mathrm{~g}$ of dry material is given in the table below (Table 5).

Table 5. The extraction yield obtained from $2 g$ of dried material.

\begin{tabular}{lllll}
\hline $\begin{array}{l}\text { Vegetable } \\
\text { powder }\end{array}$ & $\begin{array}{l}\text { Hexanic } \\
\text { extracts }\end{array}$ & $\begin{array}{l}\text { DCM } \\
\text { extracts }\end{array}$ & $\begin{array}{l}\text { Ethyl acetate } \\
\text { extracts }\end{array}$ & $\begin{array}{l}\text { Methanol } \\
\text { extracts }\end{array}$ \\
\hline $\mathrm{Ca}$ & 3,08 & 1,55 & 1,02 & 15,42 \\
$\mathrm{Cp}$ & 2,07 & 1,03 & 0,51 & 7,26 \\
$\mathrm{~Pa}$ & 3,60 & 1,54 & 1,03 & 17,51 \\
$\mathrm{Sa}$ & 2,59 & 3,21 & 1,03 & 10,38 \\
\hline
\end{tabular}

DCM: dichloromethane

The lowest yields are obtained with ethyl acetate $(0.51 \%$ $1.03 \%)$ and the highest with methanol (7.26\% - $17.51 \%)$. Although hexane yields relatively high yields, it extracts more apolar compounds than dichloromethane, which extracts relatively polar compounds. To establish the chemical profile by TLC, we retain dichloromethane and methanol which are susceptible to quantitatively resealing the compounds of interest.

\subsubsection{Ingerprinting by Thin Layer Chromatography (TLC)}

The chromatographic fingerprint was developed with the two organic extracts, the dichloromethane extract and the methanol extract. On the developed chromatogram of the dichloromethane extract (Figure 5) observed under the UV lamp at $366 \mathrm{~nm}$, there are several distinct red-dominant colour spots present throughout the sample. The developed chromatogram of the methanolic extract (Figure 6) was identified with the specific flavonoid reagent (Neu's reagent) and observed under the UV lamp at 366 $\mathrm{nm}$. There are more spots corresponding to polyphenols, especially flavonoids. The chemical profile of each extract shows different spots of different colours, the $\mathrm{R}_{f}$ values of which are also shown in the tables below (tables 6-7). For both extracts, there is a clear difference in the chemical profile of the three plants. With the dichloromethane extract, the most frequent spots are those with $\mathrm{R}_{f}$ values of 0.93 (red) and 0.62 (red). The chromatogram of the Cochlospermum planchonii sample is distinguished by the absence of the red spot and the presence of the yellow spot. Differences in chemical profiles could explain why these three plants are combined in one recipe [28]. These chromatograms could be used for routine analyses of the powder of the phytomedicament saye, for quality control of powders of future crops.

Table 6. Front reference (Rf) of major spots of the fingerprint and their coloration

\begin{tabular}{|c|c|c|c|}
\hline Sample & $\begin{array}{l}\text { Dichloromethane extracts and } \\
\text { front reference }\left(\mathbf{R}_{f}\right)\end{array}$ & $\begin{array}{l}\text { Methanol extracts and front reference }\left(\mathrm{R}_{f}\right) \\
\text { (Using Neu reagent) }\end{array}$ & Revealing \\
\hline $\mathrm{Ca}$ & $\begin{array}{l}\text { Red }(0,93) \\
\text { Dark red }(0,81) \\
\text { Red }(0,65)\end{array}$ & $\begin{array}{l}\text { Red }(0,90) \\
\text { Fluorescent Green }(0,78) \\
\text { Green }(0,65) \\
\text { Brown }(0,58) \\
\text { Orange }(0,55) \\
\text { Yellow }(0,53) \\
\text { Red }(0,27)\end{array}$ & Lamp UV $\lambda=366 \mathrm{~nm}$ \\
\hline $\mathrm{Pa}$ & $\begin{array}{l}\text { Red }(0,93) \\
\text { Light red }(0,62)\end{array}$ & $\begin{array}{l}\text { Red }(0,90) \\
\text { Green }(0,65) \\
\text { Fluorescent Blue }(0,27) \\
\text { Light blue }(0,16)\end{array}$ & Lamp UV $\lambda=366 \mathrm{~nm}$ \\
\hline
\end{tabular}


Table 7. Front reference (Rf) of major spots of the different fingerprints and their coloration.

\begin{tabular}{llll}
\hline Sample & $\begin{array}{l}\text { Dichloromethane extracts and } \\
\text { front reference }\left(\mathbf{R}_{f}\right)\end{array}$ & $\begin{array}{l}\text { Methanol extracts and front reference }\left(\mathbf{R}_{f}\right) \\
(\text { Using Neu reagent })\end{array}$ & Revealing \\
\hline \multirow{4}{*}{$\mathrm{Cp}$} & Light blue $(0,85)$ & Green $(0,75)$ & Lamp UV $\lambda=366 \mathrm{~nm}$ \\
& Green $(0,76)$ & Blue $(0,68)$ & \\
& Brown yellow $(0,66)$ & Light blue $(0,58)$ & Fluorescent Blue $(0,27)$ \\
& Green $(0,53)$ & Green $(0,16)$ & Lamp UV $\lambda=366 \mathrm{~nm}$ \\
& Red $(0,90)$ & \\
$\mathrm{Sa}$ & Red $(0,93)$ & Light green $(0,78)$ & Yellow $(0,65)$ \\
& Light yellow $(0,66)$ & Green $(0,58)$ & Fluorescent Blue $(0,27)$ \\
& Light red $(0,62)$ & Light blue $(0,16)$ & \\
\end{tabular}

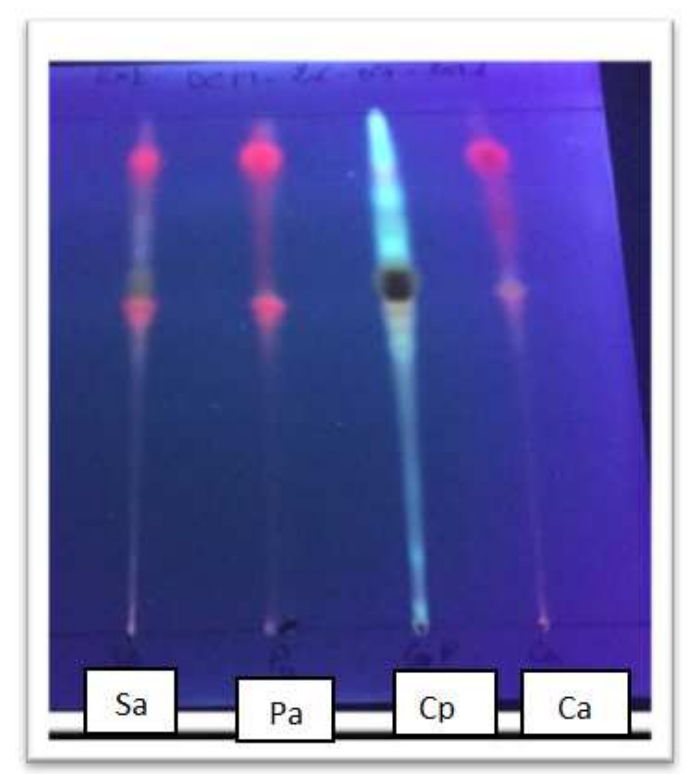

Figure 5. Chromatographic fingerprint of dichloromethane extracts.

Eluent. Toluene - ethyl acetate - acetic acid (5: 4:1) Revealing: under UV lamp $\lambda=366 \mathrm{~nm}$

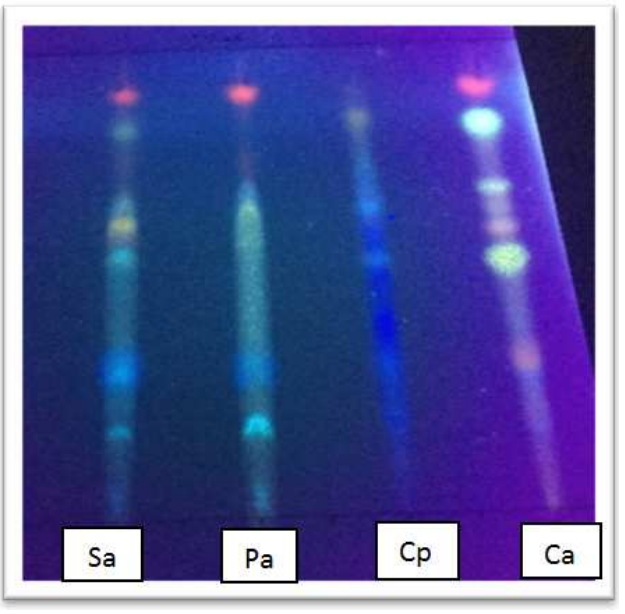

Figure 6. Chromatographic fingerprint of methanolic extracts.

Eluent. Ethyl acetate, methanol, water (7:2:1)

Revealing: under UV Lamp $\lambda=366 \mathrm{~nm}$ and using Neu reagent

\subsection{Phytochemical Screening}

The various extracts were analysed by TLC in order to highlight the chemical interest groups. The results obtained are recorded in the following table (table 8).

Table 8. Qualitative phytochemical screening.

\begin{tabular}{llllllll}
\hline \multirow{2}{*}{ Extracts of saye } & \multicolumn{2}{l}{ Chimical Groups } & & & & \\
\cline { 2 - 8 } & Sterols & Triterpenes & Flavonoïds & Tanins & Alkaloids & Coumarins & Saponins \\
\hline Hexane & + & + & - & - & - & - & - \\
Dichloromethane & + & + & + & - & - & + & + \\
Ethyl acetate & - & - & + & + & + & + & + \\
Methanol & - & - & + & + & + & - & + \\
\hline
\end{tabular}

Phytochemical screening revealed the presence of main chemical interest groups in the selective extracts of saye, namely tanins, flavonoids, saponosides, sterols, triterpenes and coumarins. This report agree with the previous report on the phytochemistry of the same traditional herbal drug [28]. For the evaluation of the total flavonoid content, We have chosen the dichloromethane extract.

\subsection{Phytochemical Screening and Determination of Flavonoids as a Chemical Marker Group}

In the literature, on the different powders that make up Saye, it has been reported that they have individual antimalarial activity [29-31]. Previous studies have reported on phytochemical screening of the mixture of the three powders (Saye) and its different components. These studies have detected the presence of polyphenols such as flavonoids in selective organic extracts [32]. In this analysis, the flavonoid content was evaluated as a chemical marker. We determined the total flavonoid content in the presence of quercetin as a reference in the DCM extract. The control tube is composed of $100 \mu \mathrm{L}$ extract and supplemented to $5 \mathrm{ml}$ with methanol. The absorbance of the quercetin $(0,10 \mathrm{mg} / \mathrm{ml})$ used as reference compound is measured under the same conditions. The tests are carried out in triplicate. The amount 
of flavonoids in the plant extract in quercetin equivalent (QE) is determined using the quercetin calibration curve (Figure 7). The total flavonoid content, based on $100 \mathrm{~g}$ dry matter, is $127,39 \mathrm{mg}$ expressed as quercetin.

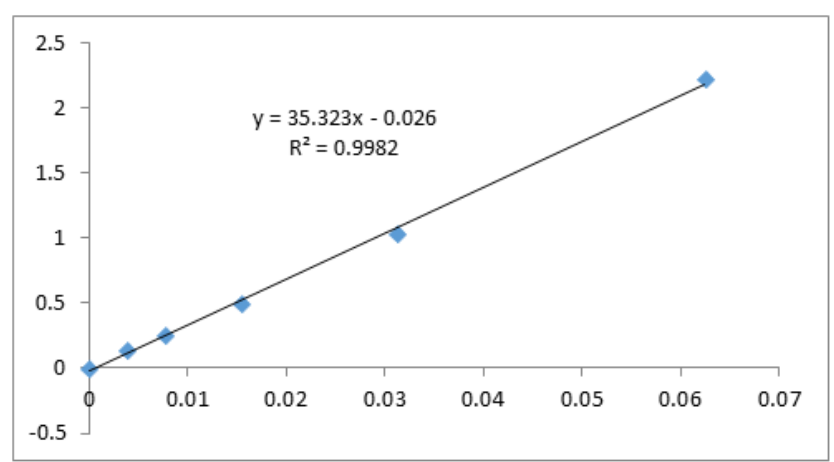

Figure 7. Calibration curve of a series of quercetin standard solutions in the determination of the flavonoid content.

\section{Conclusion}

In this study, we analyzed various parameters that are part of the Saye drug standardization process. Standardization and quality control of herbal products are essential to ensure good health coverage of the population. The indices analysed at the center of this study characterize the different powders that go into the recipe. We confirmed the existence of chemical groups by thin layer chromatography by establishing the fingerprint from the dichloromethane and methanol extracts. We have specifically chosen flavonoids as the chemical marker group. Using the UV spectrometry method, we were able to evaluate the content of this group in relation to the quercetin used as a reference. As clinical studies on saye are ongoing, these data will allow better monitoring of the quality and reproducibility of this herbal drug.

\section{References}

[1] Ekka N. R. Standardization Strategies for Herbal Drugs-An Overview Research. J. Pharm. and Tech. 2008; 1 (4): 310-312.

[2] Patil G. S. Standard Tools for Evaluation of Herbal Drugs: An Overview, the Pharma Innovation - Journal 2013; 2 (9): 60.

[3] Folashade K. O., Omoregie E. H. and Ochogu A. P. Standardization of herbal medicines - A review, International Journal of Biodiversity and Conservation 2012, 4 (3): 101-112.

[4] Bijauliya R. K., Alok S., Dilip Kumar Chanchal and Mayank Kumar. A comprehensive review on standardization of herbal drugs, International Journal of Pharmaceutical and sciences Research 2017, 8 (9): 3663-3677.

[5] Dixit V. K., Yadav N. P. Recent approaches in herbal drug standardization. Integr. Biol. 2008, 2 (3): 195-203.

[6] Patel P. M., Patel N. M., Goyal R. K. Quality control of herbal products. The Indian Pharmacist 2006, 5 (45): 26-30.

[7] Patel P., Patel N. M., Patel P. M., WHO Guidelines on Quality control of herbal medicine, International Journal of Research in Ayurveda \& Pharmacy 2011, 2 (4): 1148-1154.

[8] Patil S. G., Wagh A. S., Pawara R. C., Ambore S. M. Standard Tools for Evaluation of Herbal An Overview, the Pharma Innovation - Journal 2013, 2 (9): 60-65.

[9] Patwekar S. L., Suryawanshi A. B., Gaikwad M. S., Pedewad S. R., Potulwar A. P. Standardization of herbal drugs: An overview. The Pharma Innovation Journal 2016, 4 (9): 100104.

[10] Dakuyo Z., Meda A. L., Da O, Kiendrebeogo M., TraoreCoulibaly M., Novak J., Benoit- Vical F., Weisbord E., Willcox M. SAYE: The Story of an Antimalarial Phytomedicine from Burkina Faso. J. Altern. Complement. Med. 2015, 21: 187-195.

[11] Da O., Traore/Coulibaly M., Yerbanga R. S., Koama B., Ouedraogo N., Tamboura S., Dakuyo Z. P., Sekhoacha M. P., Nikiema J. B., Ouedraogo G. A., Matsabisa M. G., Ouedraogo J. B. Antiplasmodial andAntioxidant Activities of Saye: ATraditional Herbal Remedy for Malaria. American Journal of Biochemistry and Molecular Biology 2014, 4: 155-166.

[12] Danis M., "advances in malaria therapy in 2003" Med. Trop, 2003, 63: 267-270.

[13] White N. J. Antimalarial drug resistance. J. Clin Invest. 2004, 113 (8): 1084-1092.

[14] Ambroise-Thomas P., "Genomic, molecular biology and malaria: new medical perspectives?" Bull. Soc. Pathol. Exo., 2004, 97: 155-160.

[15] Pradines B., Vial H., Olliaro P., "malaria prophylaxisand treatment: problems, recent developments and perspectives" Med. Trop, 2003, 63: 79-98.

[16] Ambroise-Thomas P., "treatment of malaria: prevention of resistance by antimalarial drug combinations" Med. Trop., 2000, 60: 219-222).

[17] Ouédraogo S.,. Sombié C. B., Ouédraogo W. J. C., Nitiéma M., Belemnaba L., Ouédraogo S., Semdé R. Quality control of trunk's barks of Lannea microcarpa Engl. and K. Krause and Anogeissus leiocarpus (DC) Guill. \& Perr. for the manufacture of phytomedicines for the treatment of hypertension. International Journal of Phytopharmacy JulAug 2017, 7 (4): 35-40.

[18] Kassahun A., Feleke G. Chemical Composition and PhysicoChemical Analysis of Eucalyptus Globulus Leave and Oil. Science Journal of Chemistry 2019, 7 (2), 36-38.

[19] European Pharmacopoeia 6th Edition, Council of Europe. ed. European Directorate for the Quality of Medicines (EDQM); 2016, 4271: 639 .

[20] World health organization. Quality control method for herbal material. Geneva: World Health Organization 2011.

[21] AOAC. Official Methods of Analysis of AOAC International, 18th edn. AOAC International, Gaithersburg, MD, 2005.

[22] Odeja O., Obi G., Ogwuche E. C., Elemike E. E., and Oderinlo Y., Phytochemical Screening, Antioxidant and Antimicrobial activities of Senna occidentalis (L.) Leaves Extract, Journal of Clinical Phytoscience, 2015, 2-6.

[23] Harborne J. B., Phytochemical Methods: A Guide to Modern Techniques of plant Analysis. Chapman \& Hall Ltd, London, 1973, 278. 
[24] Ouédraogo B., Yoda J., Kini B. F., Koala M., Yaro A. and Bonzi-Coulibaly Y., phytochemical screening and in vitro antioxidant study of six plants used for the treatment of hypertension in traditional medicine, world journal of pharmacy and pharmaceutical sciences 2019, 8 (4): 16651678.

[25] Békro Y. A., Békro M. J. A., Boua B. B., TraBi F. H. and Ehile E. E. Ethnobotanical study and phytochemical screening of Caesalpinia benthamiana (Baill.) Herend. And Zarucchi (Caesalpiniaceae). Sciences et Nature 2007, 4: 217-225.

[26] Lehmann H. Herbal medicinal products in Europe: Status, registration, controls. University of Strasbourg. 2013, 341.

[27] Ouédraogo S., Traoré S., Yoda J., Traoré A., Traoré T. K., Lompo M., Kini BF and Ouédraogo S. Formulation and Evaluation of a Syrup Based on Balanites aegyptiaca L. Delile. Journal of Pharmaceutical Research International 2018, 23 (3): $1-9$

[28] Da O., Traoré-Coulibaly M., Ouédraogo J. C. W., Yaro B.,
Yerbanga R. S., Kini B. F., Koama B., Dakuyo Z. P., Nikiema J. B., Ouédraogo G. A., Matsabisa M. G. And Ouédraogo J. B. Phytochemical screening of Saye, a traditional herbal remedy for malaria. Int. J. Biol. Chem. Sci. 2015, 9 (6): 2940-2946.

[29] Nafiu M. O., Akanji M. A., Yakubu M. T. Phytochemical and Mineral Constituentsof Cochlospermum planchonii (Hook. Ef.x Planch) Root. Bioresearch Bulletin 2011. 5: 51-56.

[30] Hemant D., Chandewar A. V. A review on pharmacognostical, phytochemical, pharmacological properties of Phyllanthus amaru. International Journal of Biomedical And Advance Research (IJBAR) 2013, 04 (05): 281-288.

[31] Matthew O. A., Gambo N. N. Phytochemistry and Antimicrobial Activity of the Leaf of cassia alata LINN. Chemistry and Materials Research 2013, 3 (3): 96-101.

[32] Ezeja M. I., Anaga A. O. Anti-diarrhoeal Activities of the Methanolic Root Barkextract of Cochlospermum planchonii (Hook f). International Journal of Toxicological and Pharmacological Research 2010, 2 (2): 40-44. 